\title{
Phosphoric Acid
}

National Cancer Institute

\section{Source}

National Cancer Institute. Phosphoric Acid. NCI Thesaurus. Code C47670.

A colorless, odorless phosphorus-containing inorganic acid. Phosphoric acid is a sequestering agent which binds many divalent cations, including $\mathrm{Fe}++, \mathrm{Cu}++, \mathrm{Ca}++$, and $\mathrm{Mg++}$. Phosphoric acid is used in dentistry and orthodontics as an etching solution, to clean and roughen the surfaces of teeth where dental appliances or fillings will be placed. In addition, phosphoric acid is a constituent in bone and teeth, and plays a role in many metabolic processes. 